\title{
Coping and health in novice and experienced nursing students during clinical practice: a descriptive, differential and correlational analysis
}

\author{
C. Jimenez-J imenez ${ }^{1}$, J. L Sanchez-Laguna ${ }^{1}$, I. M. J imenez-Linde ${ }^{2}$ \\ 1. Department of Nursing, University of Cordoba, Córdoba, Spain. 2. Department of Psychology, University of Cordoba, \\ Córdoba, Spain.
}

Correspondence: J.L Sanchez-Laguna. Address: Department of Nursing, University of Cordoba, Avda. Menendez Pidal, s/n, 14017 Córdoba, Córdoba, Spain. Email: en1salaj@uco.es.

Received: September 14, 2012

Accepted: October 7, $2012 \quad$ Online Published: July 24, 2013

DOI : $10.5430 /$ jnep.v3n11p152

URL: http://dx.doi.org/10.5430/jnep.v3n11p152

\section{Abstract}

Aim: This study identifies the differences in novice and experienced nursing students' reports of coping and their relationship with health.

Background: Clinical practice constitutes a particularly stressful training period in an academic context that activates many coping resources in students. However, there is little empirical evidence about the coping strategies used by novice and experienced nursing students during clinical practice. Both ineffective and adaptive efforts are manifested in health (physio-psycho-social symptoms).

Methods: Cross-sectional research was performed using descriptive, differential and correlational procedures. This study was carried out with 357 students from all 3 years of a nursing diploma programme at a Spanish nursing college. Data were collected in 2008-2009.

Findings: The results indicated that problem-focused coping (PFC) was used significantly more by students than emotion-focused coping (EFC). Both first and third-year students used PFC more frequently than second-year students. In contrast, second-year students used "avoidance" strategies more frequently than first-year students. The results also showed that emotion-focused coping significantly harmed student's health during their clinical practice, while problem-focused coping tended to be associated with fewer health problems, but not significantly. These results were the same for all students irrespective of the course or experience.

Conclusion: This study provides tools for the development of prevention programmes in nursing schools based on the identification of healthy coping strategies. The paper proposes certain actions to support the development of psychoeducational stress coping programmes for clinical practice.

\section{Key words}

Coping, Clinical practice, Experience, Health, Novice, Nursing students, Stress

\section{I ntroduction}

The stress of nursing students is a relevant and current topic in literature on professional nursing ${ }^{[1,2]}$. Clinical practice constitutes a particularly stressful training period that has drawn the attention of researchers ${ }^{[3-6]}$. In a previous study ${ }^{[7]}$, 
information on the differences in novice and experienced nursing students' reports of stress and health during clinical practice was provided. As mentioned, that study was part of a global research project; hence, this first analysis should be complemented by additional successive studies to configure the overall model. The objective of the present study was to complete this by providing information on the differences in coping strategies used by nursing students based on their clinical experience and analysing their relationship with health, using the same population. The analysis of other components of the model, such as emotions and the situational and personal context of the students, will be the subject of future research.

\section{Review of literature}

Coping has been viewed as a stabilizing factor that may help individuals to maintain psychosocial adaptation during stressful events. The coping process is a very complex response that occurs when an individual attempts to remove stress or a perceived threat from the environment. Thus, the actual reaction to an environmental event may be as important as the event itself ${ }^{[8]}$. Although students cannot avoid stressors during clinical practice, their ability to cope is important for achieving success in their academic and social environments.

\subsection{Coping: identification of strategies}

A variety of coping strategies has been identified in the literature and many tools have been designed for their identification or classification ${ }^{[9]}$. However, according to Lazarus \& Folkman ${ }^{[10]}$, all of them can be summarized in two broad categories or types of stress coping strategies: problem-focused coping (PFC) and emotion-focused coping (EFC).

Twenty-six (26) studies were identified that focus on the coping strategies of nursing students. Of these, 17 examined the identification of coping strategies in nursing students.

The majority of studies reported that nursing students tend to prefer to use problem-focused strategies rather than emotion-focused strategies ${ }^{[6,11-21]}$. Other authors ${ }^{[4,22-24]}$ have reported that students mainly use emotion-focused strategies when responding to stress. However, Lo ${ }^{[25]}$, in a longitudinal study with Australian nursing students, found that students used both PFC and the EFC strategies during three training courses and no significant differences were observed.

\subsection{Coping and experience}

"The strategy or strategies which an individual uses depend both on situational and individual factors" [26]. Thus, academic characteristics such as the academic year or experience may be examples of these coping determinants ${ }^{[28]}$.

Six of the 26 studies examined the coping associated with year and clinical experience. While some authors reported coping differences in novice and experienced students ${ }^{[20,21,28,29]}$, others did not ${ }^{[25,30]}$. Specifically, Brown \& Edelmann ${ }^{[28]}$ found that students with less clinical experience use problem-focused strategies more often than more experienced students, while students who had completed their clinical training made greater use of PFC than EFC. Lo ${ }^{[25]}$, in a longitudinal study with Australian nursing students, described that students used both PFC and EFC in three training courses and no significant differences were observed. However, in a longitudinal cohort study ${ }^{[2]}$, it was noted that nursing students increased their level of stress and the use of negative coping as they advanced through the training programme. Coping strategies showed a fairly stable pattern: while the frequency of EFC (avoidance, distraction) increased, the use of PFC remained constant throughout the programme. Fernandez ${ }^{[20]}$ noted statistically significant differences in active coping, planning and self-incrimination by study year. A recent study with Chinese female nursing students showed that the use of positive coping in third year nursing students was significantly less than in first and second-year students ${ }^{[21]}$. 


\subsection{Coping and health: the relationship with biopsychosocial response to stress}

Eleven of the 26 studies ${ }^{[5,17,18,20,21,24,31-35]}$ reviewed examined the coping associated with biopsychosocial response to stress. All coincided that problem-focused coping strategies are positively associated with well-being (adaptive in this sense) while emotion-focused coping strategies increase negative symptoms (less adaptive).

\subsection{Theoretical framework}

This study used Lazarus' theoretical framework. According to this theory, coping is defined as "cognitive and behavioural efforts to manage demands that are appraised as taxing or exceeding the resources of the person" (p.141) ${ }^{[10]}$. In Lazarus' definition, coping involves efforts to alter the stressful situation (i.e. problem-focused coping), as well as efforts to regulate the emotional distress associated with the situation (i.e. emotion-focused coping). Although conceptually distinct, Lazarus suggests that both forms of coping can reduce psychological distress and that people use both problem- and emotion-focused coping in more stressful episodes. Adaptive efforts are manifested in health in three categories: moral (or subjective) welfare, social or occupational functioning and somatic health ${ }^{[36]}$. Coping and adaptive health outcomes (in terms of biopsychosocial responses) were the guiding concepts used in this research.

\section{Methods}

\subsection{Aims}

The aim of this study was to identify the differences in novice and experienced nursing students' reports of coping strategies and adaptational outcomes during their clinical practice.

The following research questions were addressed:

- What coping strategies did students frequently use to relieve their stress during periods of clinical practice?

- What were the differences in reports of coping between novice and experienced groups of nursing students?

- What coping strategies used by the students were associated with the common adaptational responses (biopsychosocial health)?

\subsection{Design}

The data reported in this paper are part of a research project undertaken within the context of the Innovation and Teaching Improvement Project promoted by the Quality Commissioner at the University of Cordoba (Andalusia, Spain). For this study, a cross-sectional design was used with a sample stratified by year. Descriptive, differential and correlational procedures were also used.

\subsection{Sampling strategy}

The participants whose data are presented in this study were nursing students at the Higher School for Nursing at Cordoba University (Andalusia, Spain) enrolled on a full-time 3-year nursing programme. The programme had 230 educational credits ( 1 credit $=10$ hours) and with an overall distribution between theory and practice of 70:30 in the first year, 50:50 in the second and 40:60 in the third. The students completed their clinical practice at different hospitals and health centres and at different times. All 512 nursing students (target population) were asked to take part in this study; 395 questionnaires were returned ( $77.1 \%$ response rate). In order to align the participants with those in the study conducted by Jimenez et al. (2010), this sample was stratified by academic year ( $\mathrm{n}=119$ in each year) and 357 were valid for analysis, representing $70 \%$ of the entire nursing student population at this University. 


\subsection{Data collection}

The data were collected over an 8-month period in 2008-2009. Two types of data collection tools were used.

1) Identification variables

To describe the sample, an ad hoc demographic data sheet was used consisting of: socio-demographic characteristics, academic characteristics and characteristics of clinical practice ${ }^{[7]}$.

2) Measurement variables

Information relating to measurement variables was compiled using two tools created specifically for this purpose by Sheu et al. ${ }^{[17]}$. With the author's permission, these tools were adapted for this research project.

The Coping Behaviour Inventory (CBI) is a tool that was created by Sheu et al. ${ }^{[17]}$ and was adapted for this study by the first author; it consists of 22 items (three more than the original) that compile information about the coping experience of nursing students during clinical practice. The questionnaire was designed in order to consider the frequency of coping. Each item was assessed using a 5-point Likert scale, ranging from ' 0 ' ("Never") to '4' ("Always"). The total scores ranged from 0 to 88. A higher score indicated more frequent use of this type of coping behaviour. The psychometric properties of this instrument indicated reasonable reliability indexes: Cronbach's $\alpha$ coefficient was $.76^{[17]}$. In the present study, the internal consistency of the questionnaire measured by Cronbach's $\alpha$ coefficient was .72. To calculate reliability in this study, the Spearman-Brown split-half method was used, giving a coefficient of .73.

In previous studies ${ }^{[7,37]}$, a factor analysis (main components and varimax rotation) was performed on the revised scale, revealing six factors or dimensions that reflected different types of coping behaviour used by students during clinical practice, accounting for $58.46 \%$ of total variance. Both the internal consistency and reliability of the first five subscales were good: Cronbach's $\alpha$ coefficient ranged from 0.87 to $0.60(p \leq .01)$ and the Spearman-Brown coefficients ranged from .94 to .65 ( $p \leq .01$ ). The sixth subscale (with two items only) showed poorer results: $\alpha=.22$.

The six factors were labelled as "Avoidance", "Problem solving", Self-confidence and optimism", "Transference", "Distancing/self-isolation", and "Seeking social support/ Facilitation". A second-order factor analysis configured the CBI in two dimensions. The second, third and sixth factors were considered "problem focused coping" whereas the first, fourth and fifth factors were considered "emotion focused coping".

The Biopsychosocial Response Scale (BPSRS) contained 22 items that referred to symptoms relating to the student's physical, psychological and social health. Each item was assessed using a 5-point Likert scale, ranging from ' 0 ' (Never) to '4' (Always). Total scores ranged from 0 to 88. A higher score indicated the presence of more symptoms and poorer biopsychosocial status. The psychometric properties of this instrument indicated reasonable reliability indexes: Cronbach's $\alpha$ coefficient was .90 and test-retest reliability for 1 week was .72 $(p=.001)$; the content validity index was $.94^{[17]}$. Other studies have provided data on the psychometric properties of the Spanish adaptation of this scale ${ }^{[7,39]}$. This study refers to its six primary factors (somatic anxiety, psychic anxiety, depressive symptoms, cognitive symptoms, neuro-vegetative symptoms and common symptoms), its two secondary scales (psychological and physiological symptoms) and the Global scale (BPSRS).

\subsection{Ethical considerations}

The University's ethics committee approved the research protocol. The students who took part in the research were unpaid volunteers.

\subsection{Data analysis}

The statistics software package SPSS-11.0 for Windows was used to analyse the data. For descriptive analysis, basic statistics (n, mean, SD, range) were calculated for items, factors and totals of CBI. The Kolmogorov-Smirnov Goodness- 
of-Fit Test was used to decide if sample data came from a normal distribution. Kendal's W-Test was used to analyse the degree of consensus among the groups of students with respect to the CBI items and factors evaluation. The Paired-Samples T Test Procedure was conducted to determine which type of coping (problem focused coping or emotion focused coping) students used with greatest intensity or most frequently. To identify the differences in novice and experienced nursing students' reports of coping strategies, different analysis were performed: ANOVAs (one way) and a post-hoc Tukey Test (when data followed a normal distribution) and ranked analyses of variance (Kruskal-Wallis H-Test) and a post hoc Mann-Whitney U-Test (when data did not follow a normal distribution).

Pearson "r" coefficients were calculated to estimate the association between health and coping measures.

\section{Results}

\subsection{Demographics}

The nursing students in this study comprised 77 men (21.6\%) and 280 women (78.4\%). The majority of students $(94.7 \%$, $\mathrm{n}=336)$ were aged between 18 and 25 with a mean age of 21.9 years $(\mathrm{SD}=3.62)$. The total number of days of clinical practice completed ranged from 4 to 150 , with a mean of 38.6 days $(\mathrm{SD}=28.9)$. In this study, only "year" was considered a variable, forming the three values taken by the independent variable: a novice group: students who were experiencing clinical practice for the first time (first-year students), and two experienced groups: students who had experienced clinical practice before (second and third-year students).

\subsection{Research questions}

\subsubsection{What coping strategies do students frequently use to relieve their stress during periods of clinical practice?}

Table 1 presents details of the coping strategies used by nursing students during clinical practice. Coping frequency was measured using the Coping Behaviour Inventory (CBI). Scores were obtained for each of the 22 items on the CBI and for the six factors, for each type of coping and for the Global Inventory. Gross scores on the Global Inventory varied between 4 and 55 with a mean of 36.7 (standardized mean $=1.67$ ). In general, students used coping strategies with moderate frequency.

Both items and factors were ranked according to coping frequency. The agreement among students from each year with the factors ranking was total $\left(\mathrm{W}=1 ; \chi^{2}=15\right.$; d.f. $\left.=5 ; p=.01\right)$ and with the items ranking was statistically significant (Kendal's $\mathrm{W}=0.977 ; \chi^{2}=61.53$; d.f. $=21 ; p<.001$ ).

To a certain extent, students used all the types of coping behaviour in the Inventory (the lowest mean score was 0.44 ). The distribution was far from normal for the Inventory (Kolmogorov-Smirnov Z Statistic $=1,801 ; p=.003$ ), but a distribution close to normal for the two subscales "Problem Focused Coping" $(Z=1,229 ; p>.05)$ and "Emotion Focused Coping" $(Z=$ 1,$111 ; p>.05$ ) was observed. Score distribution was far from normal for the 22 items and for the six factors.

Specifically, the five coping behaviours used most by students during clinical practice were: To keep an optimistic and positive attitude when dealing with everything in life (item 3), To find out well before comment or action (item 21), To see things objectively (item 6), To seek support and collaboration of others (item 20) and To employ past experience to solve problems (item 16). All these behaviours were used "Often" or "Sometimes".

The least-used coping behaviours during the clinical practice training period were: To go to my things, not to involve me in the problem (item 22), To expect miracles so one does not have to face difficulties (item 10), To cry, to feel moody, sad, 
and helpless (item 18), To quarrel with others and lose temper (item 7) and To avoid teachers (item 4). All these items were rated between the "never" and "rarely" category.

Table 1. Coping Strategies Used by Nursing Students

\begin{tabular}{|c|c|c|c|c|}
\hline $\begin{array}{l}\text { CBI (Coping Behavior Inventory) } \\
\text { Factor/Item }\end{array}$ & (a) & (b) & Media & SD \\
\hline Factor I: Avoidance $\left(\alpha=.71^{*}\right)$ & \multirow{5}{*}{6} & & 0.51 & 0.54 \\
\hline 4. To avoid teachers & & 18 & 0.57 & 0.72 \\
\hline 10. To expect miracles so one does not have to face difficulties & & 21 & 0.44 & 0.72 \\
\hline 7. To quarrel with others and lose temper & & 19 & 0.54 & 0.82 \\
\hline 18. To cry, to feel moody, sad and helpless & & 20 & 0.46 & 0.71 \\
\hline Factor II: Problem solving $\left(\alpha=.74^{*}\right)$ & \multirow{8}{*}{2} & & 2.35 & 0.59 \\
\hline 5. To set up objectives to solve problems & & 9 & 2.23 & 0.84 \\
\hline 15. To make plans. list priorities. and solve stressful events & & 12 & 1.74 & 1.00 \\
\hline 11. To find the meaning of stressful incidents & & 10 & 2.02 & 1.02 \\
\hline 6. To see things objectively & & 3 & 2.66 & 0.92 \\
\hline 2. To adopt different strategies to solve problems & & 8 & 2.32 & 0.83 \\
\hline 16. To employ past experience to solve problems & & 5 & 2.57 & 1.03 \\
\hline 21. To find out well before comment or action ${ }^{\dagger}$ & & 2 & 2.92 & 0.95 \\
\hline Factor III: Self-confidence and optimism $\left(\alpha=.87^{*}\right)$ & \multirow{4}{*}{1} & & 2.65 & 0.83 \\
\hline 9. To have confidence in overcoming difficulties & & 6 & 2.48 & 0.94 \\
\hline 14. To have confidence in performing as well as senior schoolmates & & 7 & 2.47 & 0.95 \\
\hline 3. To keep an optimistic and positive attitude in dealing with everything in life & & 1 & 3.01 & 0.90 \\
\hline Factor IV: Transference $\left(\alpha=.62^{*}\right)$ & \multirow{4}{*}{4} & 13 & 1.55 & 0.82 \\
\hline 19. To relax via TV, movies, a shower. or physical exercises (ballplaying, Jogging) & & 11 & 1.54 & 1.11 \\
\hline 12. To save time for sleep and maintain good health to face stress & & & 1.80 & 1.15 \\
\hline 8. Comer y descansar & & 14 & 1.32 & 1.00 \\
\hline Factor V: Distancing/ self-isolation $\left(\alpha=.60^{*}\right)$ & \multirow{4}{*}{5} & & 0.57 & 0.57 \\
\hline 17. To attribute to fate & & 16 & 0.70 & 0.88 \\
\hline 13. To expect others to solve the problem & & 17 & 0.59 & 0.70 \\
\hline 22. To go to my things. not to involve me in the problem ${ }^{\dagger}$ & & 22 & 0.44 & 0.71 \\
\hline Factor VI: Seeking social support/Facilitation $(\alpha=.22)$ & \multirow{3}{*}{3} & & 1.95 & 0.74 \\
\hline 1. To avoid difficulties during clinical practice & & 15 & 1.31 & 1.00 \\
\hline 20. To seek support and collaboration of others ${ }^{\dagger}$ & & 4 & 2.59 & 1.00 \\
\hline $\begin{array}{l}\text { Problem-focused coping scale: PFCS (Factos II. III y VI) (12 items) } \\
\left(\alpha=.82^{*}\right)\end{array}$ & & & 2.32 & 0.72 \\
\hline $\begin{array}{l}\text { Emotion-focused coping scale: EFCS (Factors I. IV y V) (10 items) } \\
\left(\alpha=.71^{*}\right)\end{array}$ & & & 0.87 & 0.64 \\
\hline CBI (Coping Behavior Inventory) (22 ítems) $(\alpha=.72 *)$ & \multicolumn{2}{|l|}{$\mathrm{N}=357$} & 1.67 & 0.35 \\
\hline
\end{tabular}

(a) = Factor ranking; (b) = Item ranking $\dagger$ Items in italics added to the Original CBI (Sheu et al. 2002.): $\alpha=$ Cronbach's $\alpha$ coefficient; ${ }^{*} p=.001$

As regards dimensions or factors, the most frequently used strategies were: "Self-confidence and Optimism" (Factor III), "Problem solving" (Factor II) and "Seeking social support/Facilitation" (Factor VI). These strategies constituted the "Problem Focused Coping" (PFC) subscale.

The least-used coping strategies were: "Avoidance" (Factor I), "Distancing/Self-isolation" (Factor V) and "Transference" (Factor IV). These strategies constituted the "Emotion Focused Coping" (EFC) subscale. 
Differential analysis between the two coping subscales for the total sample (Student's t-test for related samples) showed that students used problem focused strategies often significantly more than emotion focused strategies $(\mathrm{T}=36,619 ; \mathrm{gl}=$ 356; $p<.001)$. Similar results were obtained for students in each year: First Year $(\mathrm{T}=24,651 ; \mathrm{gl}=118 ; p<.001)$; Second Year $(\mathrm{T}=20,163 ; \mathrm{gl}=118 ; p<.001)$; and Third Year $(\mathrm{T}=19,484 ; \mathrm{gl}=118) ; p<.001)$. Figure 1 shows basic statistics (mean and standard deviation).

\subsubsection{How many strategies did students use?}

The Coping Behaviours Inventory (CBI) contained 22 items, 12 pertaining to the PFC subscale and 10 to the EFC subscale. The results showed that students tended to use a wide repertoire of coping strategies, The observed average of strategies used by the total sample was much higher than the average expected, reaching up to $90.8 \%$ with the PFC(Mean = 10.9; range 1-12); $76.1 \%$ with the $\mathrm{CBI}$ (Mean =16.74; range 4-22), and 53.3\% with the $\mathrm{EFC}$ (Mean = 5.33; range $0-10$ ). Similar results were obtained found for students in each year.

\subsubsection{What were the differences in reports of coping between novice and experienced groups of nursing students?}

Table 2 shows the basic statistics and results of the significant ranked ANOVA in relation to coping behaviour by year and experience.

A Kruskal-Wallis H-Test revealed statistically significant differences in 8 of 22 coping behaviours evaluated by students. Of these, five (items 6, 9, 14, 16 and 21) belonged to the PFC subscale and three (items 4. 17 and 18) to the ECE. A post-hoc Mann-Whitney U-Test showed that second year (experienced group 1) nursing students made less frequent use than third-year students (experienced group 2) of three coping behaviours related to PFC (To see things objectively, To have confidence in overcoming difficulties and To have confidence in performing as well as senior schoolmates) and one coping behaviour belonging to $\mathrm{EFC}$ (To attribute to fate).

Novice students (first year) made less frequent use than experienced students of two coping behaviours pertaining to EFC (To avoid teachers and To cry, to feel moody, sad, and helpless) and one coping behaviour belonging to PFC (To employ past experience to solve problems). On the contrary, novice students (first year) used more often than experienced a particular coping strategy that concerns PFC (“To find out well before comment or action”).

Ranked ANOVA also revealed significant differences by year of study in only one of the six factors mentioned. A post-hoc Mann-Whitney U-Test showed that novice students used "Avoidance" strategies (Factor I) less frequently than second-year students (experienced group 1).

Parametric ANOVAs were performed for two coping subscales. Figure 1 shows basic statistics (mean and standard deviation). Significant differences were only detected in PFC (F $(2 / 354)=4,213, p=.016)$. A post-hoc Tukey test showed that second year (experienced group 1) nursing students made less frequent use of PFC strategies than their colleagues (experienced group 2 or novice). No differences were observed in terms of EFC strategies ( $\mathrm{F}(2 / 354=1,895, p=.152)$.

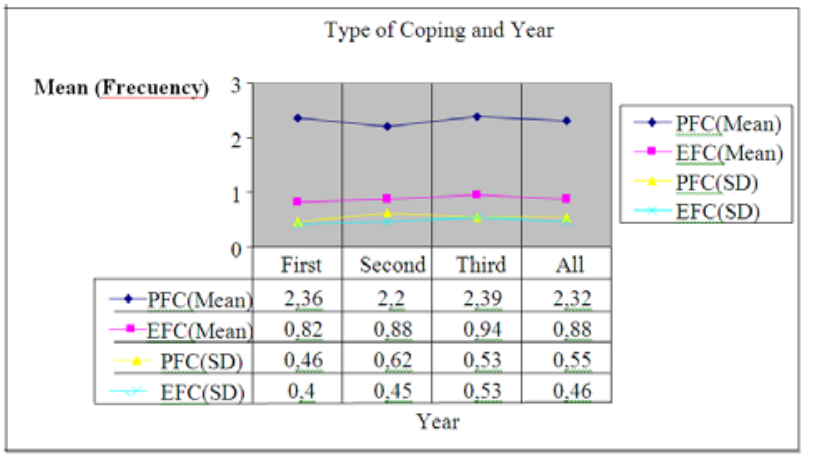


Table 2. Coping strategies by Year and by Experience groups (rankedANOVA)

\begin{tabular}{|c|c|c|c|c|c|}
\hline \multirow{2}{*}{ Dependent variables } & \multirow{2}{*}{ Year (Experiencegroups)* } & \multirow{2}{*}{ Mean Rank } & \multicolumn{3}{|c|}{ Kruskal-Wallis test } \\
\hline & & & $H\left(\chi^{2}\right.$ d.f. $\left.=2\right)$ & $P$ & $\begin{array}{l}\text { Mann-Whitney } \\
\text { U-test post hoc }\end{array}$ \\
\hline \multirow{3}{*}{ To avoid teachers } & $1^{\text {st }}$ & 155.30 & 11.895 & 0.003 & $1^{\text {st }}<2^{\text {nd }}$ or $3^{\text {rd }}$ \\
\hline & $2^{\text {nd }}$ & 190.66 & & & \\
\hline & $3^{\mathrm{rd}}$ & 191.04 & & & \\
\hline \multirow{3}{*}{ To see things objectively } & $1^{\text {st }}$ & 178.34 & 8.051 & 0.018 & $2^{\text {nd }}<3^{\text {rd }}$ \\
\hline & $2^{\text {nd }}$ & 161.53 & & & \\
\hline & $3^{\text {rd }}$ & 197.13 & & & \\
\hline \multirow{3}{*}{$\begin{array}{l}\text { To have confidence in } \\
\text { overcoming difficulties }\end{array}$} & $1^{\text {st }}$ & 183.37 & 6.453 & 0.040 & $2^{\text {nd }}<3^{\text {rd }}$ \\
\hline & $2^{\text {nd }}$ & 161.17 & & & \\
\hline & $3^{\text {rd }}$ & 192.47 & & & \\
\hline \multirow{3}{*}{$\begin{array}{l}\text { To have confidence in } \\
\text { performing as well as senior } \\
\text { schoolmates }\end{array}$} & $1^{\text {st }}$ & 181.46 & 6.191 & 0.045 & $2^{\text {nd }}<3^{\text {rd }}$ \\
\hline & $2^{\text {nd }}$ & 162.13 & & & \\
\hline & $3^{\text {rd }}$ & 193.41 & & & \\
\hline \multirow{3}{*}{$\begin{array}{l}\text { 16.To employ past experience to } \\
\text { solve problems }\end{array}$} & $1^{\text {st }}$ & 149.46 & 16.889 & 0.001 & $1^{\text {st }}<2^{\text {nd }}$ or $3^{\text {rd }}$ \\
\hline & $2^{\text {nd }}$ & 187.45 & & & \\
\hline & $3^{\text {rd }}$ & 200.08 & & & \\
\hline \multirow{3}{*}{ To attribute to fate } & $1^{\text {st }}$ & 176.98 & 6.294 & 0.043 & $2^{\text {nd }}<3^{\text {rd }}$ \\
\hline & $2^{\text {nd }}$ & 195.16 & & & \\
\hline & $3^{\text {rd }}$ & 164.86 & & & \\
\hline \multirow{3}{*}{$\begin{array}{l}\text { To cry. to feel moody. sad. and } \\
\text { helpless }\end{array}$} & $1^{\text {st }}$ & 162.87 & 9.803 & 0.007 & $1^{\text {st }}<2^{\text {nd }}$ \\
\hline & $2^{\text {nd }}$ & 197.93 & & & \\
\hline & $3^{\text {rd }}$ & 176.19 & & & \\
\hline \multirow{3}{*}{$\begin{array}{l}\text { To find out well before comment } \\
\text { or action }\end{array}$} & $1^{\text {st }}$ & 197.92 & 6.790 & 0.034 & $1^{\text {st }}>2^{\text {nd }}$ or $3^{\text {rd }}$ \\
\hline & $2^{\text {nd }}$ & 171.82 & & & \\
\hline & $3^{\text {rd }}$ & 167.26 & & & \\
\hline \multirow{3}{*}{ Factor I: Avoidance } & $1^{\text {st }}$ & 161.07 & 6.281 & 0.043 & $1^{\text {st }}<2^{\text {nd }}$ \\
\hline & $2^{\text {nd }}$ & 193.23 & & & \\
\hline & $3^{\text {rd }}$ & 182.70 & & & \\
\hline
\end{tabular}

$* 1^{\text {st }}=$ Novice group $(\mathrm{n}=119) ; 2^{\text {nd }}=$ Experienced group $1(\mathrm{n}=119) ; 3^{\text {rd }}=$ Experienced group $2(\mathrm{n}=119) ;$ All $(\mathrm{N}=357)$

\subsubsection{What coping strategies used by the students were associated with the adaptational outcomes?}

Table 3 presents the correlation coefficients between coping and health measures. These coefficients were calculated using partial correlation controlling the effects of the variable, year of study and experience. Marginally, the correlation coefficients between these two measures and the variable clustering (year/experience) were calculated. The results showed that the relationship between coping and health was independent of the variable clustering (year/experience).

The results revealed the existence of well-differentiated correlation patterns according to the type of measure of coping that was used (PFC or EFC) and within each of them, depending on the type of strategy used. Thus, PFC strategies were negatively associated with all health measures but just such a relationship is significant for only one: Depressive symptoms. However, this correlation pattern varied according to the type of PFC use. Thus, if this was related to "Problem solving" (Factor II) then it maintained the same general pattern: negative associations and a single significant relationship but this time this relationship occurred with Cognitive anxiety. If this correlation pattern concerned "Self-confidence/ 
Optimism" (Factor III), the general pattern of negative associations acquired a high and significant value with all the health measures, except with Neurovegetative specific symptoms and Physiological common symptoms. When the PFC was "Seeking social support/Facilitation" (Factor VI), the correlation pattern was more complex: this type of coping appeared to be positively and significantly associated with worse outcomes concerning Psychic anxiety, Cognitive anxiety, Psychological Symptoms and Global health.

Table 3. Correlations between coping and health measures $(\mathrm{N}=357)$

\begin{tabular}{|c|c|c|c|c|c|c|c|c|c|}
\hline \multirow{3}{*}{ Health Measures } & \multicolumn{9}{|c|}{ Coping measures\# } \\
\hline & \multirow{2}{*}{$\begin{array}{l}\text { Global } \\
\text { CBI }\end{array}$} & \multicolumn{2}{|c|}{ Subscales } & \multicolumn{6}{|c|}{ Type of strategies } \\
\hline & & $\mathrm{PFC}$ & $\mathrm{EFC}$ & $\begin{array}{l}\text { Factor } \\
\text { I }\end{array}$ & $\begin{array}{l}\text { Factor } \\
\text { II }\end{array}$ & $\begin{array}{l}\text { Factor } \\
\text { III }\end{array}$ & $\begin{array}{l}\text { Factor } \\
\text { IV }\end{array}$ & $\begin{array}{l}\text { Factor } \\
\mathrm{V}\end{array}$ & $\begin{array}{l}\text { Factor } \\
\text { VI }\end{array}$ \\
\hline \multicolumn{10}{|l|}{ Primary Factors } \\
\hline Somatic Anxiety & .072 & -.093 & $.227 * *$ & $.404 * *$ & -.047 & $-.207 * *$ & -.021 & $.201 * *$ & .065 \\
\hline Psychic Anxiety & .085 & -.032 & $.176^{* *}$ & $.262 * *$ & .018 & $-.211 * *$ & -.007 & $.191 * *$ & $.153 * *$ \\
\hline Depressive symptoms & .080 & $-.130 *$ & $.283 * *$ & $.415^{* *}$ & -.047 & $-.273^{* *}$ & -.004 & $.302 * *$ & .056 \\
\hline Cognitive anxiety & .004 & -.034 & $.120+$ & $.183 * *$ & $-.112 *$ & $-.154 * *$ & .032 & .072 & $.187 * *$ \\
\hline Neurovegetative specific symptoms. & .087 & -.025 & $.165 * *$ & $.181 * *$ & .009 & -.079 & .039 & $.175^{* *}$ & .027 \\
\hline Physiological Common symptoms & -.003 & -.067 & .100 & $.141 *$ & -.087 & -.052 & .033 & .062 & -.020 \\
\hline \multicolumn{10}{|l|}{ Secondary Scales } \\
\hline Psychological Symptoms & .074 & -.079 & $.246^{* *}$ & $.366^{* *}$ & -.057 & $-.275 * *$ & .009 & $.239 * *$ & $.180 * *$ \\
\hline Physiological Symptoms & .062 & -.090 & $.220 * *$ & $.331 * *$ & -.068 & $-.154 * *$ & .023 & $.189 * *$ & .028 \\
\hline $\begin{array}{l}\text { Global Scale } \\
\text { (BPSRS) }\end{array}$ & .088 & -.098 & $.271 * *$ & $.421 * *$ & -.052 & $-.258 * *$ & .003 & $.259 * *$ & $.116^{*}$ \\
\hline
\end{tabular}

Note. \#CBI = Coping Behavior Inventory: PFC = Problem Focused Coping; EFC = Emotion Focused Coping; Factor I: Avoidance: Factor II: Problem solving; Factor III: Self-confidence and optimism; Factor IV: Transference; Factor V: Distancing./ self-isolation; Factor VI: Seeking social support/Facilitation For $\mathrm{N}=357:{ }^{*} p=0.05 ; * * p \leq 0.01$

In contrast, EFC strategies were positively and significantly associated with all health measures (except Common physiological symptoms, whose relationship was not significant).

However this correlation pattern varied depending on the type of EFC to be used. Thus, if this concerned "Avoidance" (Factor I), the pattern was reproduced without exception; if it was Factor V, strategies on "Personal inhibition", the pattern was repeated with two exceptions (Cognitive anxiety andCommon physiological symptoms), whereas if it was "Transference" (Factor IV) strategies the correlation pattern ceased to be significant in all cases.

\section{Discussion}

The descriptive analysis showed that students tended to use a wide repertoire of coping strategies, reaching up to $90 \%$ in the case of PFC, $53 \%$ in the case of EFC and $76 \%$ for the total (CBI). This result was consistent with the results published in the revised literature that reported that clinical practice was a stressful academic context that activated many coping resources in students. However, Lindop ${ }^{[31]}$ and Tully ${ }^{[34]}$ found that students had a very small repertoire of skills in relation to coping with their feelings and stress experiences.

The results also indicated that problem-focused coping was used significantly more by students than emotion focused coping, which coincided with the results reported in most of the reviewed studies ${ }^{[17-20]}$ but differed from studies in which the most commonly-used strategies were emotion focused coping strategies ${ }^{[24,25]}$ or those that reported not differences ${ }^{[26]}$.

A core aim of this study was to examine differences in coping in novice and experienced nursing students. Differential analyses revealed that both first and third-year students used PFC more frequently than second-year students. Instead, 
second-year students used "avoidance" strategies more frequently than first year students. These findings coincided with those reported by other researchers who observed differences in coping strategies by clinical experience ${ }^{[29]}$ or year of study ${ }^{[20]}$, and partially with those described by Deary et al. ${ }^{[30]}$ who noted that the use of PFC remained constant throughout the programme while EFC strategies (avoidance, distraction) were used more frequently.

No differences were observed between year of study or experience group regarding other overall coping measures (CBI, and EFC) and most of the six specific types of coping. These findings partially agreed with those reported by $\mathrm{Lo}^{[26]}$, where students used both PFC and EFC in three training courses without any significant differences.

However, some interesting differences were observed regarding the use of specific coping strategies. Third-year students made greater use of certain "adaptive" strategies ("see things objectively", "have confidence in overcoming difficulties" and "have confidence in performing as well as senior schoolmates") than second-year students. This finding indicated a greater level of maturity and adaptation to the context of clinical training among third-year students and coincided with the findings described by Fernandez ${ }^{[20]}$, who reported that third-year students tended to use more adaptive strategies than second-year students. The strategy "To employ past experience to solve problems" was used more often by experienced than novice students; this was a good indicator of the progress and efficiency of training. The strategy "To find out well before comment or action" was used more frequently by novice than experienced students. This finding was consistent with the logic of the training process and practical training. Students starting clinical training for the first time were unaware of the clinical context and most of its procedures, techniques and protocols. All this produced higher levels of fear and insecurity ${ }^{[17,33]}$, which they tried to reduce by using this coping strategy.

It is important to highlight one type of coping, namely "Avoidance", which was used more frequently by second-year (experienced group 1) than novice students. The explanation for this finding is complex. This finding could indicate a certain sense of mistrust or fear towards staff (e.g. "avoid teachers", or indicate that experienced students (especially second-year students) were subject to greater personal and professional pressure (hence, their use of the strategy "cry, to feel moody, sad, and helpless"). There is considerable evidence here and more extensively throughout literature on nurses and nursing students to indicate that avoidance coping is ineffective coping ${ }^{[1,4,12,40]}$.

Another key aim of this study was to examine the relationship between coping and health. The effects of stress on health depend on the adequacy of coping behaviours. Coping behaviours play a vital role in the stress adjustment process. Generally speaking, literature reports that coping strategies focusing on the problem or task at hand (task-oriented approaches) seem to be associated with lower stress levels and better mental health and that emotion-focused coping strategies tend to be associated with higher stress levels and worse mental health ${ }^{[1,4,27,40]}$.

The results show that EFC significantly undermines the health of students during clinical practice, even when used infrequently, whereas PFC, which was used most, only tends to be associated with fewer problems of health and not significantly. These results were the same for all students irrespective of the year of study or experience. This may be due to the fact that the relationships between EFC and health are immediate and direct ${ }^{[17,18,24,35]}$, whereas relationships between PFC and health are mediated by other factors. Thus, Gibbons et al. ${ }^{[5]}$ explored the relationship between sources of stress and psychological well-being and considered how different sources of stress and coping resources may function as moderators and mediators on well-being. This study reported that avoidance coping was the strongest predictor of adverse well-being. Approach coping was not a predictor of well-being. The mere presence of support appeared beneficial, as well as the usefulness of that support to help students to cope.

\section{Study limitations}

Perhaps the greatest limitation of this study was that it was a cross-sectional study. Since the survey collected data at a single point in time, any changes in the participants over time were not captured. A longitudinal study would therefore be 
useful to track students in their subsequent years and explore the pattern of changes in coping and adaptational responses. This study is currently underway.

\section{Conclusions}

Both the findings reported in this study and the literature reviewed support the need to rethink clinical skills training. On this basis, the authors would like to make some suggestions for clinical practice and future studies.

The findings of this study indicate that nursing students, both novice and experienced, have a considerable repertoire of coping strategies, which can basically be classified into two broad categories or types of coping with stress: PFC and EFC. Both coping strategies had different effects on students' health.

This study identified moderately experienced students (second year) as the most problematic and less adapted to cope with the stress of clinical practice. These students not only used less "adaptive" strategies (PFC) than their schoolmates but they also used more inefficient strategies ("Avoidance"). Instead, the more experienced students (third year) were the most competent group when it came to coping with the stress of clinical practice.

From a preventive standpoint, the identification of coping strategies available to nursing students prompted us to consider the resources they used as protective factors for their health. These contributed to healthy growth and development, to the extent that they protected the individual and helped them deal with real risk situations.

At academic level, teachers must recognize that stressors exist in the clinical practice setting and understand students' adaptive responses. This knowledge could be useful for anticipating and modifying situations to prevent learning and personal development from being negatively affected. Nursing educators can help to improve students' coping skills by understanding and responding to their needs in the field of clinical training through the implementation of special programmes.

A theoretical workshop must be organised to develop important curricular content for the training of undergraduates so that students can receive basic stress coping training, particularly in the early years of their training. The development of training workshops on styles of coping through learning and the strengthening of "adaptive" strategies and the control or elimination of negative coping should also be taken in consideration during periods of clinical practice.

Finally, this study provides tools for the development of prevention programmes in nursing schools such as the identification of healthy coping strategies. It is important that such strategies are adapted to the specific context of clinical practice.

\section{Reference}

[1] Lim J, Bogossian F, Ahern K. Stress and coping in Australian nurses: a systematic review. International Nursing Review. 2010; 57: 22-31. PMid:20487471 http://dx.doi.org/10.1111/j.1466-7657.2009.00765.x

[2] Pulido-Martos M, Augusto-Landa JM, Lopez-Zafra E. Sources of stress in nursing students: a systematic review of quantitative studies. International Nursing Review. 2012; 59: 15-25. http://dx.doi.org/10.1111/j.1466-7657.2011.00939.x

[3] Zupiria X, Huitzi X, Alberdi MJ, Uranga MJ, Eizmendi I, Barandiarna M, Sanz X. Stress sources in nursing practice. Evolution during nursing training. Nurse Education Today. 2007; 27: 777-787. PMid:17187905 http://dx.doi.org/10.1016/j.nedt.2006.10.017

[4] Chan CKL, So WKW, Fong DYT. Hong Kong baccalaureate nursing students' stress and their coping strategies in clinical practice. Journal of Professional Nursing. 2009; 25 (5): 307-313. PMid:19751936 http://dx.doi.org/10.1016/j.profnurs.2009.01.018

[5] Gibbons C, Dempster M, Moutray M. Stress, coping and satisfaction in nursing students. Journal of Advanced Nursing. 2011; 67(3): 621-632. PMid:21077931 http://dx.doi.org/10.1111/j.1365-2648.2010.05495.x 
[6] Shaban IA, Khater WA, Akhu-Zehaya LM. Undergraduate nursing students' stress sources and coping behaviours during their initial period of clinical training: A Jordanian perspective, Nurse Education in Practice 2012; 12(4): 204-209. http://dx.doi.org/10.1016/j.nepr.2012.01.005.

[7] Jimenez C, Navia-Osorio PM, Diaz CV. Stress and health in novice and experienced nursing students. Journal of Advanced Nursing. 2010; 66 (2): 442-455. PMid:20423427 http://dx.doi.org/10.1111/j.1365-2648.2009.05183.x

[8] Lazarus RS. Coping Strategies. In: McHugh S, Vallis TM (eds.). Illness behavior. A multidisciplinary model. New York: Plenum Press. 1986: 303-308. http://dx.doi.org/10.1007/978-1-4684-5257-0_21

[9] Skinner, EA, Edge K, Altman J, Sherwood H. Searching for the Structure of Coping: A Review and Critique of Category Systems for Classifying Ways of Coping, Psychological Bulletin. 2003; 129(2): 216-269. PMid:12696840 http://dx.doi.org/10.1037/0033-2909.129.2.216

[10] Lazarus R.S., Folkman S. Stress, Appraisal and Coping. New York: Springer. 1984.

[11] Zweig N. Stressful events and ways of coping of baccalaureate nursing students in the clinical laboratory. Unpublished doctoral dissertation,Teachers College, Columbia University, New York. 1988. Available from: http://hdl.handle.net/10755/.

[12] Hamill C. The phenomenon of stress as perceived by Project 2000 student nurses: a case study. Journal of Advanced Nursing. 1995; 21: 528-536. PMid:7745208 http://dx.doi.org/10.1111/j.1365-2648.1995.tb02737.x

[13] Mahat G. Stress and coping: first-year nepalese nursing students in clinical settings. Journal of Nursing Education. 1996; 35(4): 163-169. PMid:8830130

[14] Mahat G. Stress and coping: junior baccalaureate nursing students in clinical settings. Nursing Forum. $1998 ; 33$ (1): $11-19$. PMid:9668813 http://dx.doi.org/10.1111/j.1744-6198.1998.tb00976.x

[15] Kirkland ML. Stressors and coping strategies among successful female African American baccalaureate nursing students. Journal of Nursing Education. 1998; 37(1): 5-14. PMid:9476729

[16] Chapman R, Orb A. Coping strategies in clinical practice: the nursing students' lived experience. Contemporary Nurse. 2001; 11: 95-102. PMid:11785870 http://dx.doi.org/10.5172/conu.11.1.95

[17] Sheu S., Lin HS, Hwang SL. Perceived stress and physio-psycho-social status of nursing students during their initial period of clinical practice. International Journal of Nursing Studies. 2002; 39: 165-175. http://dx.doi.org/10.1016/S0020-7489(01)00016-5

[18] Wang HF, Yeh MC. Stress, coping, and psychological health of vocational high school nursing students associated with a competitive entrance exam. Journal of Nursing Research. 2005; 13 (2): 106-116. PMid:15986312 http://dx.doi.org/10.1097/01.JNR.0000387532.07395.0b

[19] Hegge M, Larson V. Stressors and Coping Strategies of Students in Accelerated Baccalaureate Nursing Programs. Nurse Educator. 2008; 33 (1): 26-30. PMid:18091468 http://dx.doi.org/10.1097/01.NNE.0000299492.92624.95

[20] Fernández-Martínez ME. Perceived stress, coping strategies and sense of coherence in nursing students: Its relationship with psychological health and emocional stability. Unpublished doctoral dissertation. Department of Psychology, sociology and Philosophy. University of Leon. Spain. 2009. Available from: http://hdl.handle.net/10612/902.

[21] Ni C., Lo D., Liu X., Yang, Q., Ma J. Xu S., Li L. Chinese female nursing students' coping strategies, self-esteem and related factors in different years of school. Journal of Nursing Education and Practice 2012; 2(4): 33-41. http://dx.doi.org/10.5430/jnep.v2n4p33.

[22] Affeldt S. Perceived stress indicators and coping mechanisms among students seeking a baccalaureate degree in nursing. (Doctoral dissertation, University of South Dakota, Vermillion. Dissertation Abstracts International. 1990; 51: 4773B.

[23] Evans W, Kelly B. Pre-registration diploma student nurse stress and coping measures. Nurse Education Today. 2004; 24(6): 473-482. PMid:15312957 http://dx.doi.org/10.1016/j.nedt.2004.05.004

[24] Pryjmachukl S, Richards D. Predicting stress in pre-registration nursing students. British Journal of Health Psychology. 2007; 12: 125-144. PMid:17288670 http://dx.doi.org/10.1348/135910706X98524

[25] Lo R. A longitudinal study of perceived level of stress, coping and self-esteem of undergraduate nursing students: An Australian case study. Journal of Advanced Nursing. 2002; 39 (2): 119-126. PMid:12100655 http://dx.doi.org/10.1046/j.1365-2648.2000.02251.x

[26] Penley JA, Tomaka J, Wiebe JS. The Association of Coping to Physical and Psychological Health Outcomes: A Meta-Analytic Review. Journal of Behavioral Medicine. 2002; 25(6): 551-603. PMid:12462958 http://dx.doi.org/10.1023/A:1020641400589

[27] Folkman S, Lazarus RS. If it changes it must be a process: Study of emotion and coping during three stages of a college examination. J. Person. Soc. Psychol. 1985; 48: 150-170. PMid:2980281 http://dx.doi.org/10.1037/0022-3514.48.1.150

[28] Brown H, Edelmann R. Project 2000: A study of expected and experienced stressors and support reported by students and qualified nurses. JournalAdvanced Nursing. 2000; 31 (4): 857-864. PMid:10759982 http://dx.doi.org/10.1046/j.1365-2648.2000.01344.x

[29] Deary IJ, Watson R, Hogston R. A longitudinal cohort study of burnout and attrition in nursing students. Journal of Advanced Nursing. 2003; 43 (1): 71-81. PMid:12801398 http://dx.doi.org/10.1046/j.1365-2648.2003.02674.x 
[30] Lindop E. 1999. A comparative study of stress between pre and post-Project 2000 students. Journal of Advanced Nursing. 1999: 29(4): 967-973. http://dx.doi.org/10.1046/j.1365-2648.1999.00974.x

[31] Williams RA, Hagerty B.M, Murphy-Weinberg V, Wan J. Symptoms of depression among female nursing students. Archives of Psychiatric Nursing. 1995; 9(5): 269-278. http://dx.doi.org/10.1016/S0883-9417(95)80046-8

[32] Jones MC, Johnston DE. Distress, stress and coping in first-year student nurses. Journal of Advanced Nursing. 1997; 26(4): 75-482.

[33] Tully A. Stress, sources of stress and ways of coping among psychiatric nursing students. Journal of Psychiatric and Mental Health Nursing. 2004; 11 (1): 43-47. PMid:14723638 http://dx.doi.org/10.1111/j.1365-2850.2004.00682.x

[34] Watson R, Gardiner R, Hogston R, Gibson H, Stimpson A, Wrate R, Deary I. A study of stress and burnout in nursing students in Hong Kong: A questionnaire survey, International Journal of Nursing Studies. 2008; 45(10): 1534-1542. PMid:18241870 http://dx.doi.org/10.1016/j.ijnurstu.2007.11.003

[35] Luo Y, Wang H. Correlation research on psychological health impact on nursing students against stress, coping way and social support. Nurse Education Today. 2009; 29: 5-8. PMid:18692281 http://dx.doi.org/10.1016/j.nedt.2008.05.019

[36] Lazarus R. S. Emotion and Adaptation, New York: Oxford Press, 1991.

[37] Jimenez-Linde IM., De la Barrera E. Identificación de las estrategias de afrontamiento durante el practicum de enfermería. Referência: Scientific Journal of the Health Sciences Research Unit-Nursing. 2011; Supl. 4- III (2): 203-204. 11th Iberoamerican Conference on Nursing Education 18 al 24 Septiembre 2011. Coimbra /Portugal.

[38] Jiménez C. Impacto fisico-psico-social del Practicum de Enfermería: un estudio del estrés derivado de las prácticas clínicas sobre el estado de salud de los alumnos. Res Novae Cordubenses. Estudios de Innovación y Calidad de la Universidad de Córdoba. 2005; III: 343-373.

[39] Van der Colff JJ, Rothmann S. Occupational stress, sense of coherence, coping, burnout and work engagement of registered nurses in South Africa. SA Journal of Industrial Psychology/SATydskrif vir Bedryfsielkunde. 2009; 35(1), Art. \#423, 10 pages. http://dx.doi.org/10.4102/sajip.v35i1.423. 